University of Wollongong

Research Online

Faculty of Science, Medicine and Health -

Papers: part A

Faculty of Science, Medicine and Health

$1-1-2016$

On the intrinsic accuracy and precision of the standardised growth curve (SGC) and global-SGC (gSGC) methods for equivalent dose determination:

\title{
A simulation study
}

Jun Peng

Chinese Academy Of Sciences

Vasilis Pagonis

McDaniel College

Bo Li

University of Wollongong, bli@uow.edu.au

Follow this and additional works at: https://ro.uow.edu.au/smhpapers

Part of the Medicine and Health Sciences Commons, and the Social and Behavioral Sciences

Commons

\section{Recommended Citation}

Peng, Jun; Pagonis, Vasilis; and Li, Bo, "On the intrinsic accuracy and precision of the standardised growth curve (SGC) and global-SGC (gSGC) methods for equivalent dose determination: A simulation study" (2016). Faculty of Science, Medicine and Health - Papers: part A. 4155.

https://ro.uow.edu.au/smhpapers/4155

Research Online is the open access institutional repository for the University of Wollongong. For further information contact the UOW Library: research-pubs@uow.edu.au 


\title{
On the intrinsic accuracy and precision of the standardised growth curve (SGC) and global-SGC ( $\mathrm{SSGC}$ ) methods for equivalent dose determination: A simulation study
}

\begin{abstract}
In optically stimulated luminescence (OSL) dating, the single aliquot regenerative-dose (SAR) method has been used extensively for determining equivalent doses $(\mathrm{De})$ in quartz. A variation of the SAR method is the "standardised growth curve" (SGC) method, which has been used as an efficient procedure to save measurement time during dating studies. During the application of the SGC method one establishes the SGC and calculation of the De of an aliquot requires only measurement of the standardised natural dose signal. Recently, a "global standardised growth curve" (gSGC) method was developed as an improved version of the SGC procedure. During the application of the gSGC method, the growth curves are renormalised using sensitivity-corrected signal corresponding to one of the regenerative doses.

Subsequently the De of an aliquot is estimated using the sensitivity-corrected natural dose signal and an additional sensitivity-corrected regenerative dose signal as well as the established gSGC. In the present study, simulations are performed to assess the intrinsic accuracy and precision of the SGC and gSGC De estimates. The results of our simulations validate that the gSGC method is intrinsically more precise than the SGC method and is also more accurate for doses greater than $210 \mathrm{~Gy}$. Several factors which affect the reliability of the two methods are investigated.
\end{abstract}

\section{Keywords}

curve, growth, intrinsic, accuracy, study, simulation, determination, precision, dose, standardised, equivalent, methods, gsgc, global, sgc

\section{Disciplines}

Medicine and Health Sciences | Social and Behavioral Sciences

\section{Publication Details}

Pagonis, V., Li, B. \& Peng, J. (2016). On the intrinsic accuracy and precision of the standardised growth curve (SGC) and global-SGC (gSGC) methods for equivalent dose determination: A simulation study.

Radiation Measurements, 94 53-64. 


\title{
On the intrinsic accuracy and precision of the standardised growth curve (SGC) and global-SGC (gSGC) methods for equivalent dose determination: A simulation study
}

Jun Peng ${ }^{\mathrm{a}, \mathrm{d}}$, Vasilis Pagonis ${ }^{\mathrm{b}, *}, \mathrm{Bo} \mathrm{Li}^{\mathrm{c}}$

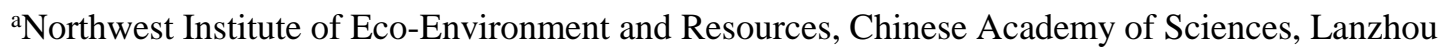
730000, China

'Physics Department, McDaniel College, Westminster, MD 21157, USA

${ }^{\mathrm{c}}$ Centre for Archaeological Science, School of Earth and Environmental Sciences, University of

Wollongong, Wollongong, NSW 2522, Australia

${ }^{\mathrm{d}}$ University of Chinese Academy of Sciences, Beijing 100049, China

Corresponding author: vpagonis@ mcdaniel.edu

\begin{abstract}
In optically stimulated luminescence (OSL) dating, the single aliquot regenerative-dose (SAR) method has been used extensively for determining equivalent doses $\left(D_{e}\right)$ in quartz. A variation of the SAR method is the "standardised growth curve" (SGC) method, which has been used as an efficient procedure to save measurement time during dating studies. During the application of the SGC method one establishes the SGC and calculation of the $D_{e}$ of an aliquot requires only measurement of the standardised natural dose signal. Recently, a "global standardised growth curve" (gSGC) method was developed as an improved version of the SGC procedure. During the application of the gSGC method, the growth curves are re-normalised using sensitivity-corrected signal corresponding to one of the regenerative doses. Subsequently the $D_{e}$ of an aliquot is estimated using the sensitivity-corrected natural dose signal and an additional sensitivity-corrected regenerative dose signal as well as the established gSGC. In the present study, simulations are performed to assess the intrinsic accuracy and precision of the SGC and gSGC $D_{e}$ estimates. The results of our simulations validate that the gSGC method is intrinsically more precise than the SGC method and is also more accurate for doses greater than $210 \mathrm{~Gy}$. Several factors which affect
\end{abstract}


the reliability of the two methods are investigated.

Keywords: Standardised growth curve, equivalent dose, kinetic simulation, re-normalisation

\section{Introduction}

Luminescence dating techniques are well-established experimental methods for determining the absorbed total cumulative dose from natural radiation sources for archaeological and geological samples (Aitken, 1998; Wintle, 2008). The single aliquot regenerative-dose (SAR) protocol (Murray and Wintle, 2000) used in optically stimulated luminescence (OSL) dating is one of the most widely used dating techniques and has been successfully applied to quartz grains from a wide variety of Quaternary sediments (Murray and Olley, 2002). During the application of the SAR method, the sensitivity-corrected natural dose signal is projected onto the growth curve that is constructed using a series of sensitivity-corrected regenerative dose signals, in order to calculate the corresponding equivalent dose $\left(\mathrm{D}_{\mathrm{e}}\right)$. The "standardised growth curve" (SGC) procedure (Roberts and Duller, 2004) has been frequently applied in combination with the SAR protocol to speed up the measurement process during $D_{e}$ determination. Roberts and Duller (2004) firstly applied the SGC method to coarse-grained quartz from Tasmania and fine polymineral grains of loess from China, and found that a universal SGC exists for samples from different continents. Lai (2006) used the SGC procedure to determine $\mathrm{D}_{\mathrm{e}}$ values of silt-sized quartz extracted from loess samples from the Chinese Loess Plateau, and concluded that a common growth curve exists for samples younger than approximately $270 \mathrm{ka}$.

Stevens et al. (2007) tested the validity of the SGC method using quartz grains obtained from samples of Chinese loess; they suggested that the SGC approach is particularly suited to high-resolution sampling studies of loess deposition, in which large numbers of samples from the same sections are analyzed. Long et al. (2010) investigated the applicability of the SGC procedure for estimating $D_{e}$ values of lacustrine sediments from the Qaidam Basin of the Qinghai-Tibetan Plateau in China, and they showed that $\mathrm{D}_{\mathrm{e}}$ values determined by the SGC approach are in agreement with those calculated based on a full SAR protocol for lacustrine samples, for dose values up to approximately $400 \mathrm{~Gy}$. Yang et al. (2011) applied the SGC method to aeolian samples collected from sand fields in northeastern China, and found that the ratio of SAR $D_{e}$ to SGC $D_{e}$ 
values fall within $\pm 10 \%$ of each other, for $\mathrm{D}_{\mathrm{e}}$ values smaller than approximately $50 \mathrm{~Gy}$.

Burbidge et al. (2006) measured quartz samples from the Old Scatness Broch and Sumburgh Hotel Gardens sites using a refined SGC method. In their experiments an extra regenerative dose point close to the expected $D_{e}$ value of each sample was used. In this way the regenerative dose predicted using the SGC can be compared with the extra regenerative dose given to each sample. This provides a check on the applicability of the SGC method employed. Telfer et al. (2008) tested the performance of the SGC method using samples from a range of environments in southern Africa and Florida. They found significant $\mathrm{D}_{\mathrm{e}}$ underestimation when using the SGC to determine $D_{e}$ values for a sample from Florida, which did not show regenerative growth characteristics in accordance with any other samples. They advocated the use of regionally based SGC for full $D_{e}$ determination, and reiterated the recommendation of Burbidge et al. (2006) to incorporate a single regenerative step in the SGC procedure, so as to check for consistency. Similarly, Shen and Mauz (2011) estimated $D_{e}$ values of late Pleistocene fine silt quartz from the Lower Mississippi Valley using the SGC method, and used the OSL response of a regenerative dose comparable in size to the expected dose to assess the reliability of $\mathrm{D}_{\mathrm{e}}$ estimates derived from the SGC method.

Recently, Li et al. (2015a, 2015b) proposed a method to reduce the effect of between-aliquot variation in growth curves, by normalising the growth curves using sensitivity-corrected signal corresponding to one of the regenerative doses; they referred to this procedure as "re-normalisation". The re-normalisation method requires the measurement of an extra sensitivity-corrected regenerative dose signal, in addition to the sensitivity-corrected natural dose signal. Li et al. (2015a) found a common re-normalised dose response curve which extended to doses of approximately 250 Gy for quartz samples with different geological provenances, sedimentary contexts and depositional ages. Their study indicated the possibility of developing a "global standardised growth curve" (gSGC) for the OSL signals from single aliquots of quartz.

The purpose of this paper is to simulate dose recovery experiments for the SGC and gSGC procedures, in order to assess the intrinsic accuracy and precision of SGC and gSGC $\mathrm{D}_{\mathrm{e}}$ estimates. The simulations are carried out using the comprehensive kinetic model for quartz developed by Bailey (2001). Several factors that can potentially affect the reliability of the methods are investigated. To the best of our knowledge, there are no published simulation studies of these methods using kinetic models. 
We investigated the relative error (RE) and relative standard deviation (RSD) of SGC and gSGC $D_{\mathrm{e}}$ estimates by simulating random variations of the concentrations of electrons and holes in the model, and also by random variation of the decay constants of the fast and medium decaying components in the OSL signal. The procedure simulates a dose recovery test, where an optically bleached "natural" quartz sample was irradiated with a laboratory dose in the range 30-300 Gy, and finally the given dose was recovered using the SGC and gSGC methods. The percentage difference between the given dose and the recovered dose denotes the RE of the methods. A Gaussian probability function was applied to the simulated $D_{e}$ values to estimate the RSD of the methods.

It should be noted that uncertainties in the $\mathrm{D}_{\mathrm{e}}$ values simulated in the present study are of a random rather than a systematic nature, and that the overall accuracy and precision of the methods will have contributions from several other factors such as photon counting statistics (Galbraith, 2002; Li, 2007; Adamiec et al., 2012; Bluszcz et al., 2015) and instrument reproducibility (Truscott et al., 2000; Thomsen et al., 2005; Jacobs et al., 2006; Duller, 2008), which are beyond the subject of this paper.

\section{Simulation of dose recovery experiments to determine SGC and gSGC $D_{e}$ estimates}

In this paper random variations in quartz samples were simulated using a Monte Carlo method, as described in detail in previous studies (Bailey, 2004; Pagonis et al., 2011a, 2011b, 2011c). The model developed by Bailey (2001) consists of five electron traps and four hole centers and is able to reliably reproduce a wide variety of TL and OSL phenomena in quartz (Bailey, 2001; Pagonis et al., 2007a, 2007b, 2008). Levels 3 and 4 in this model (usually termed the fast and medium OSL components) yield TL peaks at approximately $330{ }^{\circ} \mathrm{C}$ and give rise also to OSL signals. The OSL signals from levels 3 and 4 are most suitable for the SAR protocol, and are of particular relevance in the simulation experiments described in this paper.

The experimentally observed variability in OSL characteristics of quartz grains was simulated by allowing trap concentrations to vary randomly within $\pm 20 \%$ of the original values, using uniformly distributed random numbers. The simulations also incorporated the experimentally observed large variations of the decay constants for the fast and medium components in a quartz sample. These variations were simulated using two Gaussian distributions 
based on the experimental values of the decay constants obtained by Feathers and Pagonis (2015). The average decay constant of $10.3 \pm 3.4 \mathrm{~s}^{-1}$ was used for the fast component, and a value of $2.1 \pm 0.7 \mathrm{~s}^{-1}$ for the medium component. These values are comparable to those obtained by Duller (2012), namely $11.1 \pm 4.3 \mathrm{~s}^{-1}$ and $1.94 \pm 1.0 \mathrm{~s}^{-1}$, respectively.

The dose recovery experiments used for determining the SGC and gSGC $D_{e}$ were simulated using the open source R program KMS (Peng and Pagonis, 2016). SGC and gSGC $D_{e}$ values were calculated using the function caleD ( ) from the R package numOSL (Peng et al., 2013). In the dose recovery simulations, the burial dose (Table 1 step 5) was optically bleached in the laboratory (Table 1 step 6) and irradiated with a dose $\mathrm{D}_{\mathrm{n}}$ (Table 1 step 7) in the range 30-300 Gy. This given dose was treated as the "natural" dose to be determined using the SGC and gSGC methods. The test dose $\mathrm{D}_{t}$ was set equal to $0.1 \mathrm{D}_{\mathrm{n}}$ (Table 1 step 10). The procedure used for determining the "natural" dose using SGC and gSGC methods consists of two independent parts, as summarized in Table 1 and Table 2.

Steps $1-5$ of Table 1 are used for simulating the geological history for the quartz sample, as proposed by Bailey (2001). Steps 6-12 of Table 1 are used to simulate the sensitivity-corrected given (natural) dose signal $L_{n} / T_{n}$ used for calculating the SGC $D_{e}$. Steps 13-18 of Table 1 simulate the additional sensitivity-corrected regenerative dose signal $\mathrm{L}_{\mathrm{r}} / \mathrm{T}_{\mathrm{r}}$ required to determine the gSGC $D_{e}$. The same $L_{n} / T_{n}$ values were used for both SGC and gSGC $D_{e}$ determination with the difference being in the gSGC method the $L_{n} / T_{n}$ values were re-normalised with an additional $D_{r}$ $\left(\mathrm{L}_{\mathrm{r}} / \mathrm{T}_{\mathrm{r}}\right)$, whereas in the SGC method the $\mathrm{L}_{\mathrm{n}} / \mathrm{T}_{\mathrm{n}}$ values remained un-normalised. Table 2 lists the steps for simulating a series of sensitivity-corrected regenerative dose signals $\mathrm{L}_{\mathrm{ri}} / \mathrm{T}_{\mathrm{ri}}$, which are used to construct the growth curves required by the SGC and gSGC methods. Note that regenerative doses $\mathrm{D}_{\mathrm{ri}}$ used to construct a growth curve were measured on a single aliquot rather than on different aliquots. There are some additional steps in the simulations which are not shown explicitly in Tables 1 and 2. Specifically after each excitation stage in the simulations a relaxation period is introduced in order to allow the concentrations of electrons in the conduction band and holes in the valence band to decay to negligible values (Pagonis et al., 2006). After each heating step the model simulates a cooling-down period with a constant cooling rate of $-5{ }^{\circ} \mathrm{C} \mathrm{s}^{-1}$. Readers are referred to the paper by Peng and Pagonis (2016) for details of these additional steps used in the simulations. 
Each random growth curve is constructed using five regenerative dose points $\mathrm{D}_{\mathrm{ri}}$ (Table 2), which are chosen in such a way that the resultant sensitivity-corrected regenerative dose signals $\mathrm{L}_{\mathrm{r} i} / \mathrm{T}_{\mathrm{ri}}$ encompass the sensitivity-corrected given (natural) dose signal $\mathrm{L}_{\mathrm{n}} / \mathrm{T}_{\mathrm{n}}$. Sensitivity-corrected given (natural) dose and additional regenerative dose signals were used in combination with randomly simulated growth curves, to determine the SGC and gSGC $D_{e}$ values. The specific details of these steps are presented in the next section.

In this paper, unless otherwise stated, the simulations were repeated using 500 randomly generated versions of parameters for each given dose point, and 6 aliquots (growth curves) were used to construct the average dose response curve (re-normalised dose response curve) for determination of the SGC (gSGC) $D_{e}$ values. During simulation of the gSGC $D_{e}$ values, unless otherwise stated, the fourth regenerative dose $\mathrm{D}_{\mathrm{r} 4}\left(\mathrm{~L}_{\mathrm{r} 4} / \mathrm{T}_{\mathrm{r} 4}\right)$ was used to re-normalise the growth curves (i.e., $\mathrm{L}_{\mathrm{r} i}^{\prime} / \mathrm{T}_{\mathrm{ri}}^{\prime}=\left[\mathrm{L}_{\mathrm{r}} / \mathrm{T}_{\mathrm{ri}}\right] /\left[\mathrm{L}_{\mathrm{r}} / \mathrm{T}_{\mathrm{r} 4}\right]$, where $\mathrm{L}_{\mathrm{ri}}^{\prime} / \mathrm{T}_{\mathrm{ri}}^{\prime}$ denotes the re-normalised sensitivity-corrected regenerative dose signals), and the additional regenerative dose $D_{r}$ required for determining the gSGC $D_{e}$ was set equal to $0.8 D_{n}$. The average dose response curve (re-normalised dose response curve) was fitted using a single saturating exponential function in order to calculate the SGC (gSGC) $D_{e}$.

We obtained decay rates for the fast and medium components by deconvoluting simulated decay curves into two first-order exponential decaying components as well as a constant component using the decomp () function from the R package numOSL. We obtained the characteristic saturation dose $D_{0}$ values by fitting the growth curves with the single saturating exponential model using the fitGrowth () function from the R package numOSL. The resultant variations in simulated natural dose signal intensity, ratio of fast to medium decay rates, and characteristic saturation dose $\mathrm{D}_{0}$ were demonstrated in Fig. 1A, B, and C, respectively, for a given dose of $240 \mathrm{~Gy}$. The \% variations of these parameters are generally within the ranges of typical experimental OSL data.

Fig. 2A and B show the sensitivity-corrected regenerative dose signals $L_{\mathrm{ri}} / T_{\mathrm{ri}}$ and their re-normalised counterpart $\mathrm{L}_{\mathrm{ri}}^{\prime} / \mathrm{T}_{\text {ri }}^{\prime}$ correspondingly, for 3000 randomly simulated growth curves for a given dose of $240 \mathrm{~Gy}$. These figures demonstrate that the re-normalisation procedure used in the gSGC procedure can reduce significantly the scatter of the sensitivity-corrected regenerative dose signals. Specifically, if we denote the fifth sensitivity-corrected regenerative dose signal before 
and after re-normalisation as $\mathrm{L}_{\mathrm{r} 5} / \mathrm{T}_{\mathrm{r} 5}$ and $\mathrm{L}_{\mathrm{r} 5}^{\prime} / \mathrm{T}_{\mathrm{r} 5}^{\prime}$, respectively, then the RSD in $\mathrm{L}_{\mathrm{r} 5} / \mathrm{T}_{\mathrm{r} 5}$ is $6.18 \%$. The RSD for $\mathrm{L}_{\mathrm{r} 5}^{\prime} / \mathrm{T}_{\mathrm{r} 5}^{\prime}$ reduces to $2.73 \%$ if the third regenerative dose $\mathrm{D}_{\mathrm{r} 3}\left(\mathrm{~L}_{\mathrm{r} 3} / \mathrm{T}_{\mathrm{r} 3}\right)$ is used to re-normalise the growth curve (i.e., $\mathrm{L}_{\mathrm{r} i}^{\prime} / \mathrm{T}_{\mathrm{ri}}^{\prime}=\left[\mathrm{L}_{\mathrm{r} i} / \mathrm{T}_{\mathrm{ri}}\right] /\left[\mathrm{L}_{\mathrm{r} 3} / \mathrm{T}_{\mathrm{r} 3}\right]$ ) (Fig. $2 \mathrm{~A}$ ). The RSD for $\mathrm{L}_{\mathrm{r} 5}^{\prime} / \mathrm{T}_{\mathrm{r} 5}^{\prime}$ is further reduced to $1.15 \%$ if the fourth regenerative dose $\mathrm{D}_{\mathrm{r} 4}\left(\mathrm{~L}_{\mathrm{r} 4} / \mathrm{T}_{\mathrm{r} 4}\right)$ is used for re-normalisation (i.e., $\left.\mathrm{L}_{\mathrm{ri}}^{\prime} / \mathrm{T}_{\mathrm{ri}}^{\prime}=\left[\mathrm{L}_{\mathrm{r} i} / \mathrm{T}_{\mathrm{ri}}\right] /\left[\mathrm{L}_{\mathrm{r}} / \mathrm{T}_{\mathrm{r} 4}\right]\right)$ (Fig. $\left.2 \mathrm{~B}\right)$.

Fig. $2 \mathrm{C}$ and $\mathrm{D}$ show the simulated $\mathrm{D}_{\mathrm{e}}$ distributions obtained from the SGC and gSGC methods respectively, for a given dose of $240 \mathrm{~Gy}$, visualized by a simplified (pseudo) radial plot (Galbraith, 1988) implemented using function psRadialPlot () from the R package numOSL. The recovered average $\mathrm{D}_{\mathrm{e}}$ values using the SGC and gSGC methods are $244.82 \mathrm{~Gy}$ and $239.62 \mathrm{~Gy}$ respectively. The standard deviations of the 500 model variants calculated from the SGC and gSGC methods are 27.25 Gy and 5.40 Gy respectively. Accordingly, the RSD for the SGC and gSGC De estimates are $11.13 \%$ and $2.25 \%$, respectively. The over-dispersion values (Galbraith et al., 1999) for the recovered SGC and gSGC $D_{e}$ distributions are $9.14 \pm 0.39 \%$ and $0.21 \pm 0.16 \%$ respectively. These simulation results suggest that the gSGC method can greatly improve the precision of $\mathrm{D}_{\mathrm{e}}$ estimates over the SGC method.

Fig. 3 shows a comparison of recovered $D_{e}$ estimates obtained by the SGC and gSGC methods for given doses $D_{n}$ in the range 30-300 Gy. It can be observed from Fig. 3 that for given doses less than 120 Gy the differences in RSD and RE between SGC and gSGC $D_{e}$ values are smaller than $4 \%$. The difference in RSD between $\mathrm{D}_{\mathrm{e}}$ estimates obtained from the two methods increases substantially when the given dose exceeds 120 Gy. However, the overall differences in RE are smaller than $3 \%$ for investigated dose values up to $300 \mathrm{~Gy}$. The simulation indicates that the gSGC method can significantly improve the precision of $D_{e}$ estimates compared to the SGC method, though the difference in accuracy between $D_{e}$ estimates obtained from the two methods is not very significant for given dose less than $210 \mathrm{~Gy}$.

\section{Investigation of factors influencing the reliability of the SGC and gSGC $D_{e}$ estimates}

In this section, we investigate the effect of various parameters on the reliability of the SGC and gSGC $D_{e}$ estimates; these parameters are the characteristic saturation dose $\mathrm{D}_{0}$ of a growth curve, the number of aliquots used for SGC and gSGC establishment, the size of the additional regenerative dose $D_{r}\left(L_{r} / T_{r}\right)$ used for re-normalising the sensitivity-corrected natural dose signal, 
and the size of the regenerative dose $\mathrm{D}_{\mathrm{ri}}\left(\mathrm{L}_{\mathrm{ri}} / \mathrm{T}_{\mathrm{ri}}\right)$ used for re-normalising the growth curves. It deserves to point out that it is not always the case that the sensitivity-corrected natural dose signal and the growth curves should be re-normalised by regenerative dose of the same magnitude (i.e., $D_{\mathrm{r}}$ may not be equal to $\mathrm{D}_{\mathrm{ri}}$ ) during gSGC $\mathrm{D}_{\mathrm{e}}$ estimation. A researcher may use an additional regenerative dose $D_{r}$ that is different in magnitude from all of the $D_{r i}$ values but close in size to the given dose $D_{n}$ for re-normalising the sensitivity-corrected natural dose signal in order to improve the precision of calculated gSGC $\mathrm{D}_{\mathrm{e}}$.

We simulated the dose recovery experiments using different values for the kinetic parameter $\mathrm{N}_{8}$ (i.e., the total concentration of holes for the "luminescence center" $\mathrm{L}$ ), in order to change the characteristic saturation dose $\mathrm{D}_{0}$ of the generated random growth curves. It was found in the simulations that as the value of the parameter $\mathrm{N}_{8}$ is increased in the model, the sensitivity of the simulated signals will also increase. Specifically larger values of $\mathrm{N}_{8}$ yield greater signal intensity for both the regenerative dose OSL response $\mathrm{L}_{\mathrm{ri}}$ and for the test dose OSL response $\mathrm{T}_{\mathrm{ri}}$. Furthermore, simulated $\mathrm{L}_{\mathrm{ri}}$ and $\mathrm{T}_{\mathrm{ri}}$ with greater signal intensity result in simulated growth curves which tend to saturate at lower doses. Consequently, a larger $\mathrm{N}_{8}$ value results in smaller $\mathrm{D}_{0}$ values for the growth curves, and vice versa.

Fig. 4 illustrates random growth curves and sensitivity-corrected given (natural) dose signals simulated using the SGC method. Fig. 4A, C, and E show respectively distributions of 3000 variants of random growth curves simulated using $\mathrm{N}_{8}$ values of $1 \times 10^{6}, 1 \times 10^{11}$, and $1 \times 10^{16} \mathrm{~cm}^{-3}$ for a given dose $\mathrm{D}_{\mathrm{n}}=240 \mathrm{~Gy}$. The corresponding characteristic saturating dose $\mathrm{D}_{0}$ are $200.60 \pm 17.00$ Gy, $165.53 \pm 15.81 \mathrm{~Gy}$, and $127.76 \pm 13.87 \mathrm{~Gy}$, respectively. It suggests that the variability in growth curves is insignificant for regenerative dose below $100 \mathrm{~Gy}$, and it increases substantially with increase in regenerative dose afterwards. This also implies that the observed larger uncertainty in SGC $D_{e}$ estimates of Fig. 3 is mainly caused by the large variability of growth curves for regenerative dose above $100 \mathrm{~Gy}$; it is concluded that the SGC method cannot effectively eliminate the between-aliquot scatter of different growth curves.

Fig. 4B, D, and F illustrate the effect of $\mathrm{D}_{0}$ values on the distributions of sensitivity-corrected given (natural) dose signal $L_{n} / T_{n}$. The RSD of $L_{n} / T_{n}$ for low, intermediate and high $\mathrm{N}_{8}$ values are $2.7 \%, 4.3 \%$, and $5.7 \%$ respectively, suggesting that the variability of $\mathrm{L}_{\mathrm{n}} / \mathrm{T}_{\mathrm{n}}$ increases as the $\mathrm{D}_{0}$ values decrease. The uncertainty of resultant $S G C D_{e}$ estimates also increases as $D_{0}$ decreases. 
These results are consistent with Fig. 4A, C, and E, which demonstrates that the RSD of sensitivity-corrected regenerative dose signals $\mathrm{L}_{\mathrm{ri}} / \mathrm{T}_{\mathrm{ri}}$ increases as $\mathrm{D}_{0}$ decreases.

Fig. 5 shows the same data as in Fig. 4 (the data was re-normalised using the gSGC method). In Fig. 5A, C, and $\mathrm{E}$, the simulated growth curves were re-normalised using the fourth regenerative dose $\mathrm{D}_{\mathrm{r} 4}\left(\mathrm{~L}_{\mathrm{r}} / \mathrm{T}_{\mathrm{r} 4}\right)$ (i.e., $\left.\mathrm{L}_{\mathrm{r}}^{\prime} / \mathrm{T}_{\mathrm{ri}}^{\prime}=\left[\mathrm{L}_{\mathrm{ri}} / \mathrm{T}_{\mathrm{ri}}\right] /\left[\mathrm{L}_{\mathrm{r}} / \mathrm{T}_{\mathrm{r} 4}\right]\right)$. In Fig. 5B, D, and F, the simulated sensitivity-corrected given (natural) dose signal was re-normalised using an additional regenerative dose $\mathrm{D}_{\mathrm{r}}\left(\mathrm{L}_{\mathrm{r}} / \mathrm{T}_{\mathrm{r}}\right)$ and the established gSGC according to Eq. (10) of Li et al. (2015a). We denote this re-normalised sensitivity-corrected natural dose signal by $L_{n}^{\prime} / T_{n}^{\prime}$. It can be seen from Fig. $5 \mathrm{~A}, \mathrm{C}$, and $\mathrm{E}$ that $\mathrm{D}_{0}$ values of the re-normalised growth curves are the same as those in Fig. 4A, C, and E, suggesting that the re-normalisation procedure will not affect the $\mathrm{D}_{0}$ values of the growth curves.

It can be observed from contrasting Fig. 4 and Fig. 5 that the variability of growth curves decreased significantly after applying the re-normalisation procedure. The scatter in re-normalised growth curves is not only small for regenerative dose less than $100 \mathrm{~Gy}$ but also less significant for larger regenerative doses (Fig. 5), in comparison to that illustrated in Fig. 4. The RSD of $\mathrm{L}_{\mathrm{n}} / \mathrm{T}^{\prime}{ }_{\mathrm{n}}$ for low, intermediate, high $\mathrm{N}_{8}$ values are $0.7 \%, 1.1 \%$, and $1.3 \%$ respectively. These values are significantly smaller than those obtained in Fig. 4 for their un-normalised counterparts. A comparison between Fig. 4 and Fig. 5 clearly illustrates why the uncertainty of $D_{e}$ estimates obtained from the gSGC method is significantly smaller than the ones obtained from the SGC method. The gSGC method reduces the variation in growth curves, to a much greater extent than the SGC method.

Fig. 6 demonstrates the variation of RSD and RE of SGC and gSGC $D_{e}$ estimates with the $\mathrm{D}_{0}$ $\left(\mathrm{N}_{8}\right)$. It can be seen from the scales of the y-axes that generally both the RSD and RE of $\mathrm{D}_{\mathrm{e}}$ estimates obtained from the gSGC method are smaller than their SGC counterpart (except the $\mathrm{D}_{\mathrm{n}}=120$ Gy case). There is no obvious correlation between the RE of SGC and gSGC $\mathrm{D}_{\mathrm{e}}$ estimates and the characteristic saturation dose $\mathrm{D}_{0}$ for various given doses. In most cases, the $\mathrm{D}_{\mathrm{e}}$ estimates yield lower RE (smaller than $4 \%$ ) using moderate $\mathrm{D}_{0}$ values corresponding to the default $\mathrm{N}_{8}$ value of $1 \times 10^{11} \mathrm{~cm}^{-3}$ used in the model of Bailey (2001). A monotonic decrease in the RSD of SGC and gSGC $D_{e}$ estimates with increased $D_{0}$ values was observed in almost all cases. This is because both the scatter in sensitivity-corrected natural dose and regenerative dose signals (as well as their 
re-normalised counterparts) decreases with the increase in $\mathrm{D}_{0}$ values, as was illustrated in Fig. 4 and Fig. 5.

During the application of the SGC (gSGC) method, the SGC (gSGC) used for $\mathrm{D}_{\mathrm{e}}$ determination is usually established from the average of a number of growth curves (re-normalised growth curves) from different aliquots. Fig. 7 demonstrates the variation of RSD and RE of SGC and gSGC $D_{e}$ estimates with the number of aliquots used for SGC and gSGC establishment. It can be observed from Fig. 7 that increasing the number of aliquots improves the precision of SGC and gSGC $D_{e}$ estimates. This is because of overall improvements of the statistics; the uncertainty of the average dose response curve (re-normalised dose response curve) used to determine the SGC (gSGC) $\mathrm{D}_{\mathrm{e}}$ values will decrease by using more aliquots in the procedure.

Using more aliquots also improves the accuracy of SGC $D_{\mathrm{e}}$ estimates, as illustrated in Fig. 7A, C, and E. However, it seems that the accuracy of gSGC $\mathrm{D}_{\mathrm{e}}$ estimates is not sensitive to the variation of number of aliquots, and shows a random variation pattern. This may imply that in the gSGC method the number of aliquots used for gSGC establishment is not a major factor controlling the accuracy of $\mathrm{D}_{\mathrm{e}}$ estimates.

In most cases both the RSD and RE of $\mathrm{D}_{\mathrm{e}}$ estimates obtained from the gSGC method are significantly smaller than their SGC counterpart. An exception is that the RE of gSGC $\mathrm{D}_{\mathrm{e}}$ estimates is slightly larger than that obtained by the SGC method for a given dose $D_{n}=120$ Gy when the number of aliquots exceed 6, as demonstrated in Fig. 7A and B. This may suggest that when applying the gSGC method to determining $D_{e}$ values smaller than $120 \mathrm{~Gy}$, the gain in accuracy is not obvious compared to the SGC method. This is consistent with Fig. 3, which suggests that the difference in RE between the two methods is less than $1 \%$ for given dose up to 210 Gy.

The re-normalisation procedure used in the gSGC method requires a sensitivity-corrected regenerative dose signal to be measured, in addition to the sensitivity-corrected natural dose signal. These signals are used in combination with the established gSGC in order to determine the gSGC $D_{e}$ value. Fig. 8 plots the RSD and RE of gSGC $D_{e}$ estimates against the size of the additional regenerative dose $D_{r}$. The results indicate that the size of the regenerative dose $D_{r}\left(L_{r} / T_{r}\right)$ used for re-normalising the sensitivity-corrected natural dose signal can significantly affect the precision of gSGC $D_{e}$ estimates (Fig. 8A). Recovered gSGC $D_{e}$ values for different given doses are of low 
RSD (smaller than $4 \%$ ), if the additional regenerative dose $D_{r}$ varies between $0.8 D_{n}$ and $1.2 D_{n}$. The gSGC $D_{\mathrm{e}}$ estimates have the lowest RSD when the additional regenerative dose is set equal to the given dose (i.e., if $D_{r}=D_{n}$ ). The RSD of gSGC $D_{e}$ estimates become increasingly larger with the increase in the difference between $D_{n}$ and $D_{r}$. The simulation validates the conclusion drawn by $\mathrm{Li}$ et al. (2015a) that the chosen additional regenerative dose should be as close as possible in size to that of the natural dose, in order to minimize the scatter in the re-normalised sensitivity-corrected natural dose signal $\mathrm{L}_{\mathrm{n}}^{\prime} / \mathrm{T}_{\mathrm{n}}^{\prime}$.

However, there is no obvious correlation between the accuracy of gSCG $\mathrm{D}_{\mathrm{e}}$ estimates and the size of the additional regenerative dose $\mathrm{D}_{\mathrm{r}}\left(\mathrm{L}_{\mathrm{r}} / \mathrm{T}_{\mathrm{r}}\right)$ (Fig. 8B). In addition, the best accuracy of gSGC $D_{e}$ estimates does not correspond to an additional regenerative dose that is equal in size to the given dose. Interestingly, for given dose $\mathrm{D}_{\mathrm{n}}=60 \mathrm{~Gy}$ and $\mathrm{D}_{\mathrm{n}}=120 \mathrm{~Gy}, \mathrm{gSGC} \mathrm{D}_{\mathrm{e}}$ estimates have the lowest RE when the additional regenerative dose $D_{r}$ is equal to $1.6 D_{n}$. For given dose $D_{n}=240$ Gy and $D_{n}=300 \mathrm{~Gy}$, gSGC $D_{e}$ estimates have the lowest RE when the additional regenerative doses are set equal to $0.6 \mathrm{D}_{\mathrm{n}}$ and $0.4 \mathrm{D}_{\mathrm{n}}$, respectively. This suggests that the correlation between accuracy of gSGC $D_{e}$ estimates and the size of additional regenerative doses used for re-normalisation is complex, and does not follow a specific pattern. It seems that lower RE is obtainable when smaller additional regenerative dose is used for re-normalisation of a larger given dose, and vice versa.

Li et al. (2015a) illustrated how the choice of the size of the regenerative dose $\mathrm{D}_{\mathrm{ri}}\left(\mathrm{L}_{\mathrm{r}} / \mathrm{T}_{\mathrm{ri}}\right)$ used for re-normalising the growth curves affects the extent of variation between aliquots (growth curves). During the simulation it was observed that the scatter in re-normalised growth curves varies slightly when different regenerative doses $\mathrm{D}_{\mathrm{ri}}\left(\mathrm{L}_{\mathrm{ri}} / \mathrm{T}_{\mathrm{ri}}\right)$ were used for re-normalisation of the growth curves, as demonstrated in Fig. 9 for a given dose of 240 Gy. The resultant mean RSD of $\mathrm{L}_{\mathrm{ri}}^{\prime} / \mathrm{T}_{\text {ri }}^{\prime}$ were $2.73 \%, 2.31 \%, 2.61 \%$, and $3.29 \%$ respectively if regenerative dose values of $0.4 \mathrm{D}_{\mathrm{n}}$, $0.8 \mathrm{D}_{\mathrm{n}}, 1.2 \mathrm{D}_{\mathrm{n}}$, and $1.6 \mathrm{D}_{\mathrm{n}}$ Gy were used for growth curve re-normalisation. Fig. 10 shows the influences of the size of the regenerative dose $\mathrm{D}_{\mathrm{ri}}\left(\mathrm{L}_{\mathrm{ri}} / \mathrm{T}_{\mathrm{ri}}\right)$ used for re-normalising the growth curves on the RSD and RE of gSGC $D_{e}$ estimates for different given doses. It can be observed from Fig. 10 that there is no obvious variation trend for the RSD or RE of gSGC $D_{e}$ estimates with the regenerative dose $\mathrm{D}_{\mathrm{ri}}\left(\mathrm{L}_{\mathrm{ri}} / \mathrm{T}_{\mathrm{ri}}\right)$ used for re-normalisation. It can be seen from the scales of y-axes in Fig. 10 that the influence of the regenerative dose sizes used for growth curve 
re-normalisation on the RSD and RE of gSGC $D_{e}$ estimates is relatively insignificant. For all the four investigated regenerative dose points, the variations in RSD and RE of gSGC $\mathrm{D}_{\mathrm{e}}$ estimates are less than $0.1 \%$.

\section{Conclusions}

The comprehensive quartz model of Bailey (2001) was used in this paper to simulate dose recovery experiments to assess the intrinsic precision and accuracy of the SGC and gSGC $D_{e}$ estimates. The simulation results show that the gSGC method can significantly improve the precision of $D_{e}$ estimates compared to the SGC method. It suggests that the difference in RE between the SGC and gSGC methods is less than $3 \%$ for investigated doses up to $300 \mathrm{~Gy}$. However, the RSD of gSGC $D_{e}$ estimates was significantly smaller than that of SGC $D_{e}$ estimates. The simulation experiments validate that the between-aliquot scatter in growth curves can be effectively eliminated by using the re-normalisation procedure employed in the gSGC method.

Several factors which may be affecting both the intrinsic precision and the accuracy of the two methods were investigated. The simulation results suggest that:

(1) The precision of SGC and gSGC $D_{e}$ estimates can be improved if growth curves with larger characteristic saturation dose $\mathrm{D}_{0}$ are used.

(2) Using a larger number of aliquots (growth curves) to establish the SGC can improve both precision and accuracy of $S G C D_{e}$ estimates. However, though the precision of $g S G C D_{e}$ estimates also improves with the increase in the number of aliquots used for gSGC establishment, it seems that the accuracy of gSGC $D_{e}$ estimates is not sensitivity to variation in number of aliquots.

(3) The precision of gSGC $D_{e}$ estimates is very sensitive to the size of the additional regenerative dose $D_{r}\left(L_{r} / T_{r}\right)$ used for re-normalising the sensitivity-corrected natural dose signal. Better precision is obtainable if the additional regenerative dose $\mathrm{D}_{\mathrm{r}}$ used for re-normalisation is close in size to the given dose $D_{n}$.

(4) Both the precision and accuracy of gSGC $\mathrm{D}_{e}$ estimates are insensitive to the size of the regenerative dose $D_{\mathrm{ri}}\left(\mathrm{L}_{\mathrm{ri}} / \mathrm{T}_{\mathrm{ri}}\right)$ used for re-normalising the growth curves. For doses up to $300 \mathrm{~Gy}$, the variations in RSD and RE of gSGC $\mathrm{D}_{\mathrm{e}}$ estimates are less than $0.1 \%$ when different regenerative dose sizes $D_{\text {ri }}$ were used for re-normalisation.

The simulation results presented in this study demonstrate that the gSGC method is almost 
always intrinsically more precise than the SGC method given that a proper size of additional regenerative dose $D_{r}\left(L_{r} / T_{r}\right)$ is used for re-normalisation. Furthermore, although the difference in accuracy between the two methods is less significant for given doses less than $210 \mathrm{~Gy}$, the gSGC method is obviously more accurate for larger doses. Therefore, we recommend use of gSGC method for future dating application if possible.

\section{Acknowledgements}

We thank both reviewers for their very extensive and thoughtful comments. The comments and suggestions of the reviewers have improved the manuscript significantly.

\section{References}

Adamiec, G., Heer, A.J., Bluszcz, A., 2012. Statistics of count numbers from a photomultiplier tube and its implications for error estimation. Radiat. Meas. 47 (9), 746-751.

Aitken, M.J., 1998. An introduction to optical dating: the dating of Quaternary sediments by the use of photon-stimulated luminescence. Oxford University Press, Oxford.

Bailey, R.M., 2001. Towards a general kinetic model for optically and thermally stimulated luminescence of quartz. Radiat. Meas. 33 (1), 17-45.

Bailey, R.M., 2004. Paper I-simulation of dose absorption in quartz over geological timescales and its implications for the precisionand accuracy of optical dating. Radiat. Meas. 38 (3), 299-310.

Bluszcz, A., Adamiec, G., Heer, A.J., 2015. Estimation of equivalent dose and its uncertainty in the OSL SAR protocol when count numbers do not follow a Poisson distribution. Radiat. Meas. $81,46-54$.

Burbidge, C.I., Duller, G.A.T., Roberts, H.M., 2006. De determination for young samples using the standardised OSL response of coarse-grain quartz. Radiat. Meas. 41 (3), 278-288.

Duller, G.A.T., 2008. Single-grain optical dating of Quaternary sediments: why aliquot size matters in luminescence dating. Boreas 37 (4): 589-612.

Duller, G.A.T., 2012. Improving the accuracy and precision of equivalent doses determined using the optically stimulated luminescence signal from single grains of quartz. Radiat. Meas. 47 (9), 770-777. 
Feathers, J.K., Pagonis, V., 2015. Dating quartz near saturation-Simulations and application at archaeological sites in South Africa and South Carolina. Quat. Geochronol. 30, 416-421.

Galbraith, R.F., 1988. Graphical display of estimates having differing standard errors. Technometrics 30, 271-281.

Galbraith, R. F., 2002. A note on the variance of a background-corrected OSL count. Anc. TL 20 (2), 49-51.

Galbraith, R.F., Roberts, R.G., Laslett, G.M., Yoshida, H., Olley, J.M., 1999. Optical dating of single and multiple grains of quartz from Jinmium rock shelter, northern Australia: Part I, experimental design and statistical models. Archaeometry 41 (2), 339-364.

Jacobs, Z., Duller, G.A.T,, Wintle, A.G., 2006. Interpretation of single grain De distributions and calculation of De. Radiat. Meas. 41 (3): 264-277.

Lai, Z.P., 2006. Testing the use of an OSL standardised growth curve (SGC) for De determination on quartz from the Chinese Loess Plateau. Radiat. Meas. 41 (1), 9-16.

Li, B., 2007. A note on estimating the error when subtracting background counts from weak OSL signals. Anc. TL 25 (1), 9-14.

Li, B., Roberts, R.G., Jacobs, Z., Li, S.H., 2015a. Potential of establishing a 'global standardised growth curve' (gSGC) for optical dating of quartz from sediments. Quat. Geochronol. 27, 94-104

Li, B., Roberts, R.G., Jacobs, Z., Li, S.H., Guo, Y.J., 2015b. Construction of a 'global standardised growth curve' (gSGC) for infrared stimulated luminescence dating of K-feldspar. Quat. Geochronol. 27, 119-130.

Long, H., Lai, Z.P., Fan, Q.S., Sun, Y.J., Liu, X.J., 2010. Applicability of a quartz OSL standardised growth curve for De determination up to $400 \mathrm{~Gy}$ for lacustrine sediments from the Qaidam Basin of the Qinghai-Tibetan Plateau. Quat. Geochronol. 5 (2-3), 212-217.

Murray, A.S., Olley, J.M., 2002. Precision and accuracy in the optically stimulated luminescence dating of sedimentary quartz: a status review. Geochronometria 21, 1-16.

Murrary, A.S., Wintle, A.G., 2000. Luminescence dating of quartz using an improved single-aliquot regenerative-dose protocol. Radiat. Meas. 32 (1), 57-73.

Pagonis, V., Adamiec, G., Athanassas, C., Chen, R., Baker, A., Larsen, M., Thompson, Z., 2011 a. Simulations of thermally transferred OSL signals in quartz: Accuracy and precision of the 
protocols for equivalent dose evaluation. Nucl. Instrum. Meth. Phys. Res. B 269 (12), $1431-1443$.

Pagonis, V., Baker, A., Larsen, M., Thompson, Z., 2011b. Precision and accuracy of two luminescence dating techniques for retrospective dosimetry: SAR-OSL and SAR-ITL. Nucl. Instrum. Meth. Phys. Res. B 269 (7), 653-663.

Pagonis, V., Balsamo, E., Barnold, C., Duling, K., McCole, S., 2008. Simulations of the predose technique for retrospective dosimetry and authenticity testing. Radiat. Meas. 43 (8), $1343-1353$.

Pagonis, V., Chen, R., George, Kitis., 2011c. On the intrinsic accuracy and precision of luminescence dating techniques for fired ceramics. J. Archaeol. Sci. 38 (7), 1591-1602.

Pagonis, V., Chen, R., Wintle, A.G., 2007a. Modelling thermal transfer in optically stimulated luminescence of quartz. J. Phys. D Appl. Phys. 40 (4), 998-1006.

Pagonis, V., Kitis, G., Furetta, C., 2006. Numerical and practical exercises in Thermoluminescence. Springer Science and Business Media, New York.

Pagonis, V., Wintle, A.G., Chen, R., 2007b. Simulations of the effect of pulse annealing on optically-stimulated luminescence of quartz. Radiat. Meas. 42 (10), 1587-1599.

Peng, J., Dong, Z.B., Han, F.Q., Long, H., Liu, X.J., 2013. R package numOSL: numeric routines for optically stimulated luminescence dating. Anc. TL 31 (2), 41-48. URL: http://CRAN.R-project.org/package=numOSL.

Peng, J., Pagonis, V., 2016. Simulating comprehensive kinetic models for quartz luminescence using the R program KMS. Radiat. Meas. 86, 63-70. URL: https://github.com/pengjunUCAS/KMS.

Roberts, H.M., Duller, G.A.T., 2004. Standardised growth curves for optical dating of sediment using multiple-grain aliquots. Radiat. Meas. 38 (2), 241-252.

Shen, Z.X., Mauz, B., 2011. Estimating the equivalent dose of late Pleistocene fine silt quartz from the Lower Mississippi Valley using a standardized OSL growth curve. Radiat. Meas. 46 (8), 649-654.

Stevens, T., Armitage, S.J., Lu, H.Y., Thomas, D.S.G., 2007. Examining the potential of high sampling resolution OSL dating of Chinese loess. Quat. Geochronol. 2 (1-4), 15-22. Telfer, M.W., Bateman, M.D., Carr, A.S., Chase, B.M., 2008. Testing the applicability of a 
standardized growth curve (SGC) for quartz OSL dating: Kalahari dunes, South African coastal dunes and Florida dune cordons. Quat. Geochronol. 3 (1-2), 137-142.

Thomsen, K.J., Murray, A.S., Bøtter-Jensen, L., 2005. Sources of variability in OSL dose measurements using single grains of quartz. Radiat. Meas. 39 (1), 47-61.

Truscott, A.J., Duller, G.A.T., Bøtter-Jensen, L., Murray, A.S., Wintle, A.G., 2000. Reproducibility of optically stimulated luminescence measurements from single grains of $\mathrm{Al}_{2} \mathrm{O}_{3}: \mathrm{C}$ and annealed quartz. Radiat. Meas. 32 (5-6), 447-451.

Wintle, A.G., 2008. Fifty years of luminescence. Archaeometry 50 (2), 276-312.

Yang, L.H., Lai, Z.P., Long, H., Zhang, J.R., 2011. Construction of a quartz OSL standardised growth curve (SGC) for aeolian samples from the Horqin dunefield in Northeastern China. Geochronometria 38 (4), 391-396. 
Table 1 Simulation steps used to generate the sensitivity-corrected natural dose signal $L_{n} / T_{n}$ and an additional sensitivity-corrected regenerative dose signal $L_{\mathrm{r}} / T_{\mathrm{r}}$.

1 Natural quartz sample: Set all trap populations to zero

2 Geological dose: 1000 Gy at $1 \mathrm{~Gy} \mathrm{~s}^{-1}$ at $20^{\circ} \mathrm{C}$

3 Geological time: Heat to $350{ }^{\circ} \mathrm{C}$

4 Repeated daylight exposures over long time: Illuminate for $100 \mathrm{~s}$ at $200{ }^{\circ} \mathrm{C}$

5 Burial dose: $20 \mathrm{~Gy}$ at $220{ }^{\circ} \mathrm{C}$ at $0.01 \mathrm{~Gy} \mathrm{~s}^{-1}$

6 Laboratory bleaching: Optical stimulation at $125^{\circ} \mathrm{C}$ for $100 \mathrm{~s}$

7 Give laboratory dose: $\mathbf{D}_{\mathbf{n}}$ Gy at $1 \mathrm{~Gy} \mathrm{~s}^{-1}$ at $20^{\circ} \mathrm{C}$

8 Preheat to $260{ }^{\circ} \mathrm{C}$ for $10 \mathrm{~s}$

9 Optical stimulation at $125^{\circ} \mathrm{C}$ for $100 \mathrm{~s}\left(\right.$ record $\left.\mathbf{L}_{\mathbf{n}}\right)$

10 Give test dose $\mathbf{D}_{\mathbf{t}}=0.1 \mathbf{D}_{\mathbf{n}}$ Gy at $1 \mathrm{~Gy} \mathrm{~s}^{-1}$ at $20{ }^{\circ} \mathrm{C}$

11 Preheat to $220{ }^{\circ} \mathrm{C}$ for $10 \mathrm{~s}$

12 Optical stimulation at $125^{\circ} \mathrm{C}$ for $100 \mathrm{~s}\left(\operatorname{record} \mathbf{T}_{\mathbf{n}}\right)$

13 Give regenerative dose: $\mathbf{D}_{\mathbf{r}}$ Gy at $1 \mathrm{~Gy} \mathrm{~s}^{-1}$ at $20^{\circ} \mathrm{C}\left(\mathbf{D}_{\mathbf{r}}=0.8 \mathbf{D}_{\mathbf{n}}\right)$

14 Preheat to $260{ }^{\circ} \mathrm{C}$ for $10 \mathrm{~s}$

15 Optical stimulation at $125^{\circ} \mathrm{C}$ for $100 \mathrm{~s}\left(\right.$ record $\left.\mathbf{L}_{\mathbf{r}}\right)$

16 Give test dose $\mathbf{D}_{\mathbf{t}}=0.1 \mathbf{D}_{\mathbf{n}}$ Gy at $1 \mathrm{~Gy} \mathrm{~s}^{-1}$ at $20^{\circ} \mathrm{C}$

17 Preheat to $220{ }^{\circ} \mathrm{C}$ for $10 \mathrm{~s}$

18 Optical stimulation at $125^{\circ} \mathrm{C}$ for $100 \mathrm{~s}\left(\right.$ record $\left.\mathbf{T}_{\mathbf{r}}\right)$ 
Table 2 Simulation steps used to generate a series of sensitivity-corrected regenerative dose signals $\mathrm{L}_{\mathrm{ri}} / \mathrm{T}_{\mathrm{ri}}$ to construct random growth curves.

1-5 Steps 1-5 are the same as in Table 1

6 Laboratory bleaching: Optical stimulation at $125^{\circ} \mathrm{C}$ for $100 \mathrm{~s}$

7 Irradiate sample with regenerative dose $\mathbf{D}_{\text {ri }}($ for $\mathrm{i}=1,2,3,4,5)$

$\left(\mathbf{D}_{\mathbf{r} 1}=0.01 \mathbf{D}_{\mathbf{n}}, \mathbf{D}_{\mathbf{r} 2}=0.4 \mathbf{D}_{\mathbf{n}}, \mathbf{D}_{\mathbf{r} 3}=0.8 \mathbf{D}_{\mathbf{n}}, \mathbf{D}_{\mathbf{r} 4}=1.2 \mathbf{D}_{\mathbf{n}}, \mathbf{D}_{\mathbf{r} 5}=1.6 \mathbf{D}_{\mathbf{n}}\right)$

8 Preheat to $260{ }^{\circ} \mathrm{C}$ for $10 \mathrm{~s}$

9 Optical stimulation at $125^{\circ} \mathrm{C}$ for $100 \mathrm{~s}\left(\right.$ record $\left.\mathbf{L}_{\text {ri }}\right)$

10 Give test dose $\mathbf{D}_{\mathbf{t}}=0.1 \mathbf{D}_{\mathbf{n}}$ Gy at $1 \mathrm{~Gy} \mathrm{~s}^{-1}$ at $20^{\circ} \mathrm{C}$

11 Preheat to $220{ }^{\circ} \mathrm{C}$ for $10 \mathrm{~s}$

12 Optical stimulation at $125^{\circ} \mathrm{C}$ for $100 \mathrm{~s}\left(\right.$ record $\left.\mathbf{T}_{\mathbf{r i}}\right)$

13 Repeat steps 7-12 with a subsequent regenerative dose $\mathbf{D}_{\mathbf{r i}}$ 

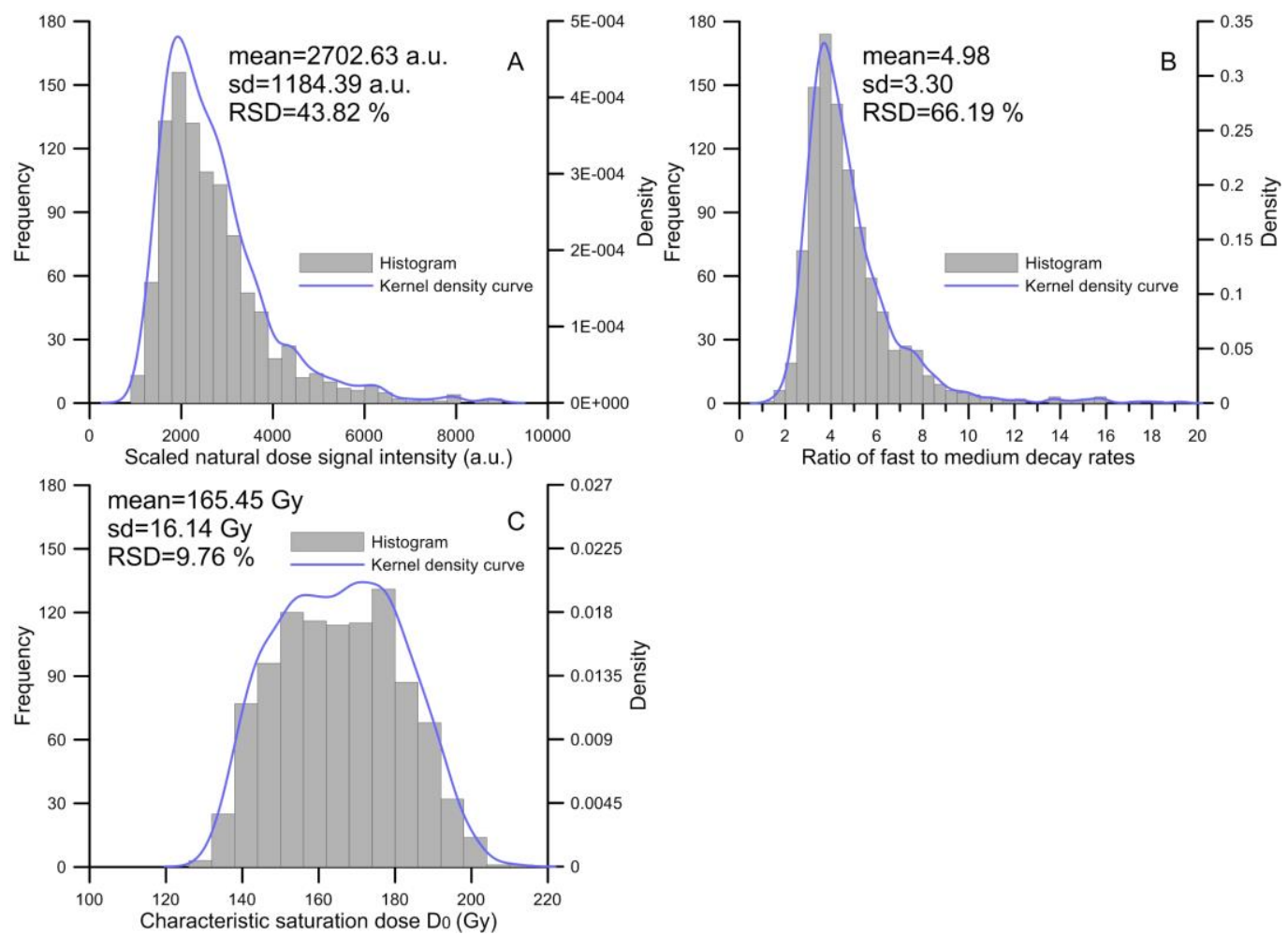

Fig. 1. Histograms and kernel density curves for simulated natural dose signal intensity (A), ratio of fast to medium decay rates (B), and characteristic saturation dose $\mathrm{D}_{0}(\mathrm{C})$ for a given dose of 240 Gy. The number of simulations was 1000 . 

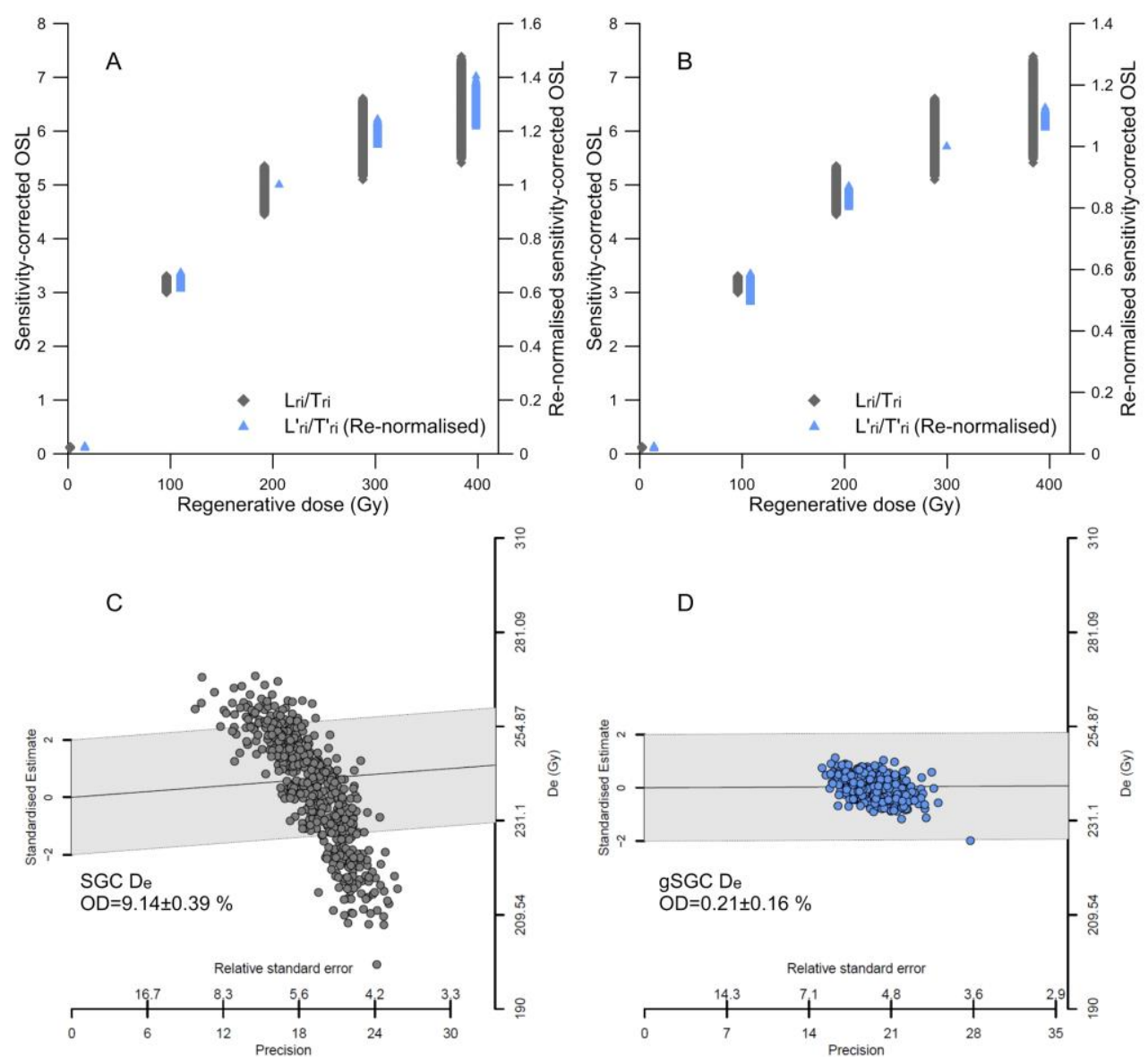

Fig. 2. (A) and (B) show the simulated sensitivity-corrected regenerative dose signals $L_{r} / T_{r i}$ (grey points) from 3000 random growth curves and their re-normalised counterpart $\mathrm{L}_{\mathrm{r} i}^{\prime} / \mathrm{T}_{\mathrm{ri}}^{\prime}$ (blue points) for a given dose $D_{n}=240$ Gy. The five regenerative dose points used for growth curve construction are $2.4,96,192,288$, and $384 \mathrm{~Gy} . \mathrm{L}_{\mathrm{ri}}^{\prime} / \mathrm{T}_{\mathrm{ri}}^{\prime}$ values in (A) and (B) are re-normalised using the third (i.e., $\mathrm{L}_{\mathrm{ri}}^{\prime} / \mathrm{T}_{\mathrm{ri}}^{\prime}=\left[\mathrm{L}_{\mathrm{r}} / \mathrm{T}_{\mathrm{ri}} \mathrm{i} /\left[\mathrm{L}_{\mathrm{r} 3} / \mathrm{T}_{\mathrm{r} 3}\right]\right.$ ) and fourth (i.e., $\mathrm{L}_{\mathrm{ri}}^{\prime} / \mathrm{T}_{\mathrm{ri}}^{\prime}=\left[\mathrm{L}_{\mathrm{ri}} / \mathrm{T}_{\mathrm{ri}}\right] /\left[\mathrm{L}_{\mathrm{r}} 4 / \mathrm{T}_{\mathrm{r} 4}\right]$ ) regenerative doses, respectively. It should be noted that the SGC is normally plotted as sensitivity-corrected regenerative dose signal multiplied by test dose (i.e., $\left[\mathrm{L}_{\mathrm{ri}} / \mathrm{T}_{\mathrm{ri}}\right] \times \mathrm{D}_{\mathrm{t}}$ ) but the multiplication is not necessary internally within this study because the same test dose magnitude was used for growth curves simulated for the same given dose. Note that the re-normalised data are offset by a few Gy to the right on the x-axis for clarity. (C) and (D) show pseudo radial plots of simulated $500 \mathrm{D}_{\mathrm{e}}$ values obtained from the SGC and gSGC methods respectively, for a given dose of $240 \mathrm{~Gy}$. gSGC $\mathrm{D}_{\mathrm{e}}$ values demonstrated in (D) were calculated using randomly simulated re-normalised sensitivity-corrected regenerative dose signals shown in (B). OD denotes the calculated over-dispersion using the central age model of Galbraith et al. (1999). 


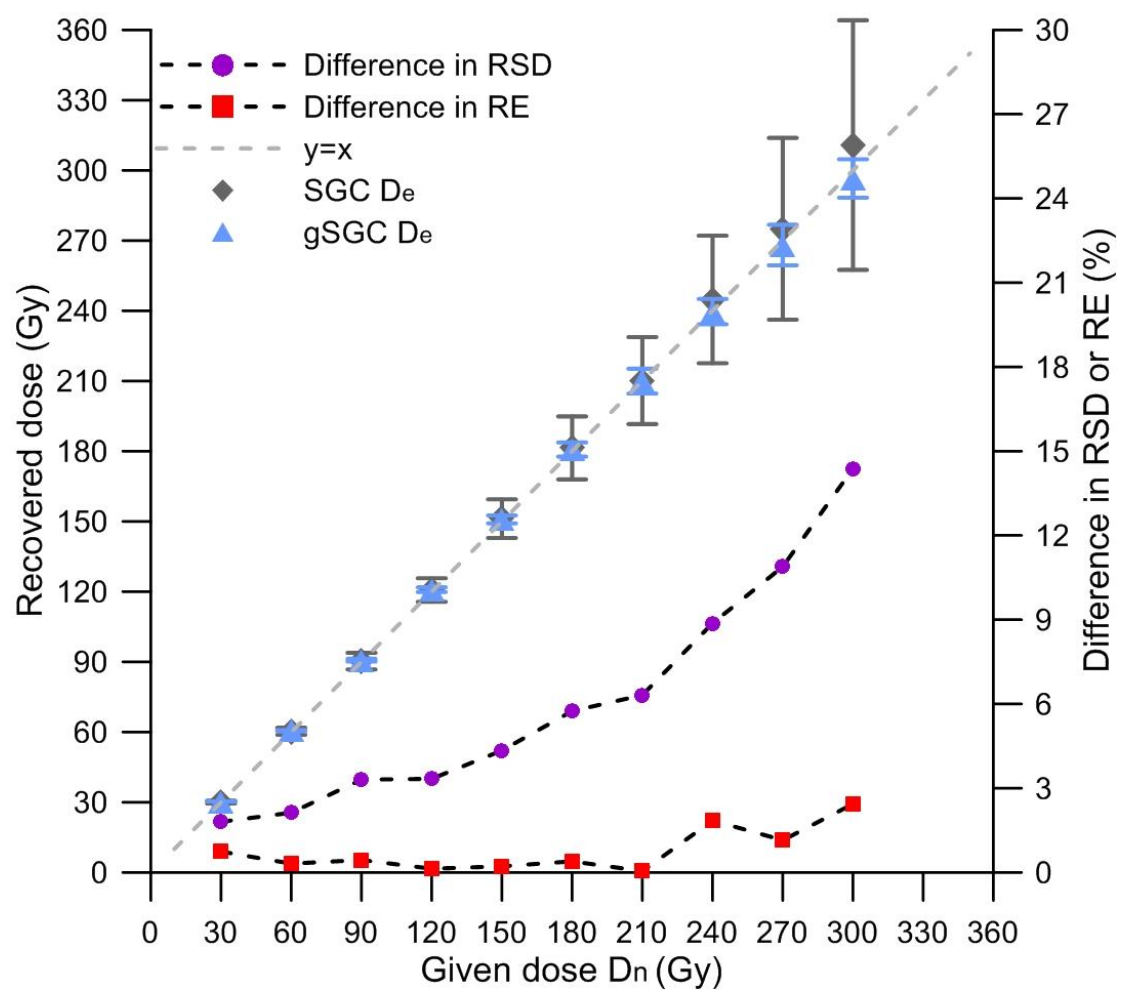

Fig. 3. The results of the SGC and gSGC simulations for given doses $D_{n}$ in the range $30-300 \mathrm{~Gy}$. The average doses were calculated using 500 versions of random parameters. The error bars denote the standard deviation of the 500 model variants. RSD and RE differences between the SGC and gSGC $D_{e}$ estimates were indicated by purple circle and red rectangle, respectively. 

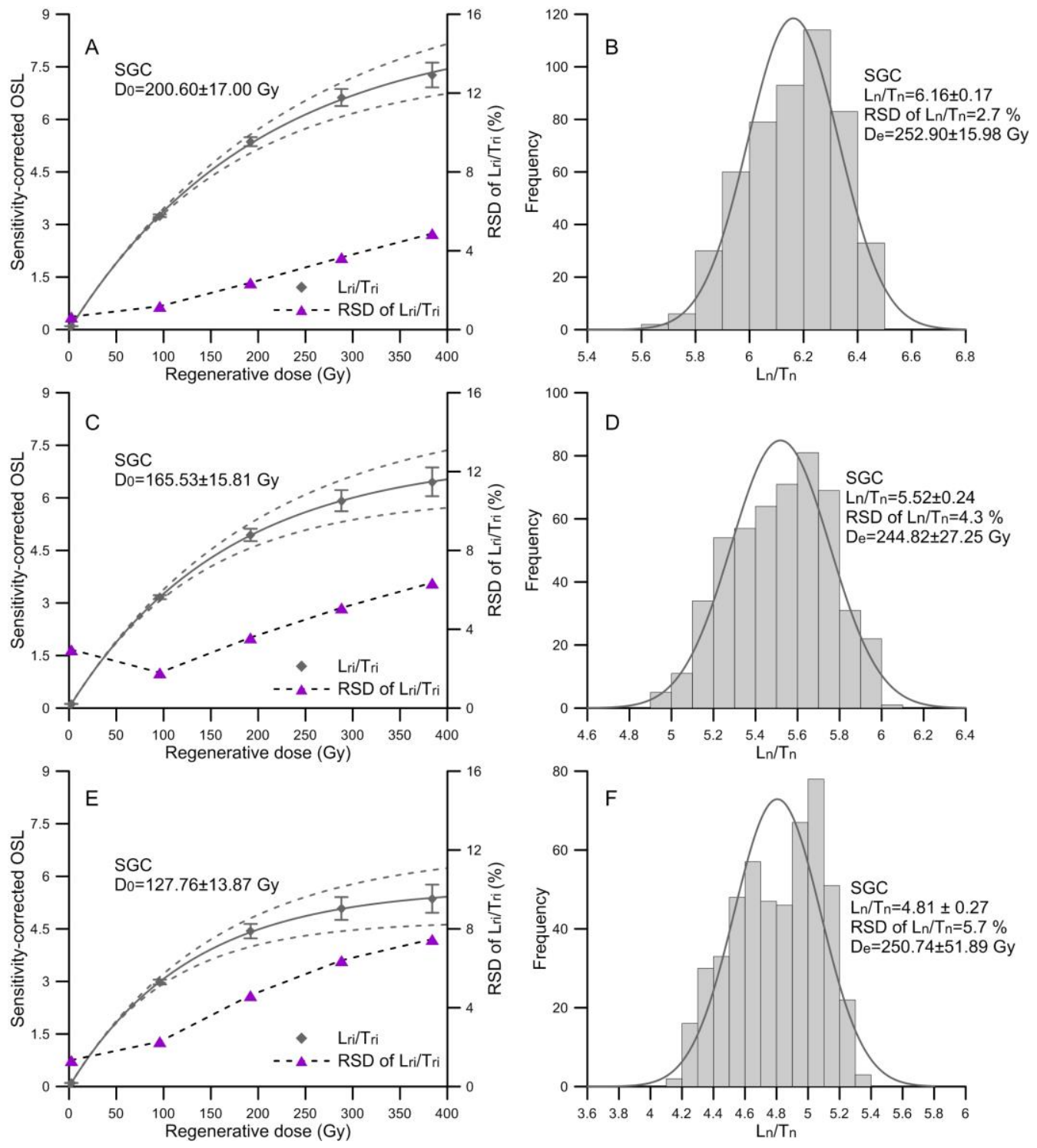

Fig. 4. (A), (C), and (E) are the result of averaging 3000 simulated random growth curves for a given dose $\mathrm{D}_{\mathrm{n}}=240 \mathrm{~Gy}$, using $\mathrm{N}_{8}$ values of $1 \times 10^{6}, 1 \times 10^{11}$, and $1 \times 10^{16} \mathrm{~cm}^{-3}$, respectively. The regenerative dose points used to construct the growth curves are 2.4, 96, 192, 288, and $384 \mathrm{~Gy}$. Two additional growth curves indicated by dashed lines denote the $95 \%$ confidence limits of the simulated $\mathrm{L}_{\mathrm{r}} / \mathrm{T}_{\mathrm{ri}}$ values. (B), (D), and (F) are the distributions of 500 simulated sensitivity-corrected given (natural) dose signal $\mathrm{L}_{\mathrm{n}} / \mathrm{T}_{\mathrm{n}}$ for a given dose of $240 \mathrm{~Gy}$, using $\mathrm{N}_{8}$ values of $1 \times 10^{6}, 1 \times 10^{11}$, and $1 \times 10^{16} \mathrm{~cm}^{-3}$, respectively. The resulting distributions of the $500 \mathrm{~L}_{\mathrm{n}} / \mathrm{T}_{\mathrm{n}}$ values were fitted with Gaussian distributions, as indicated by the grey lines. 

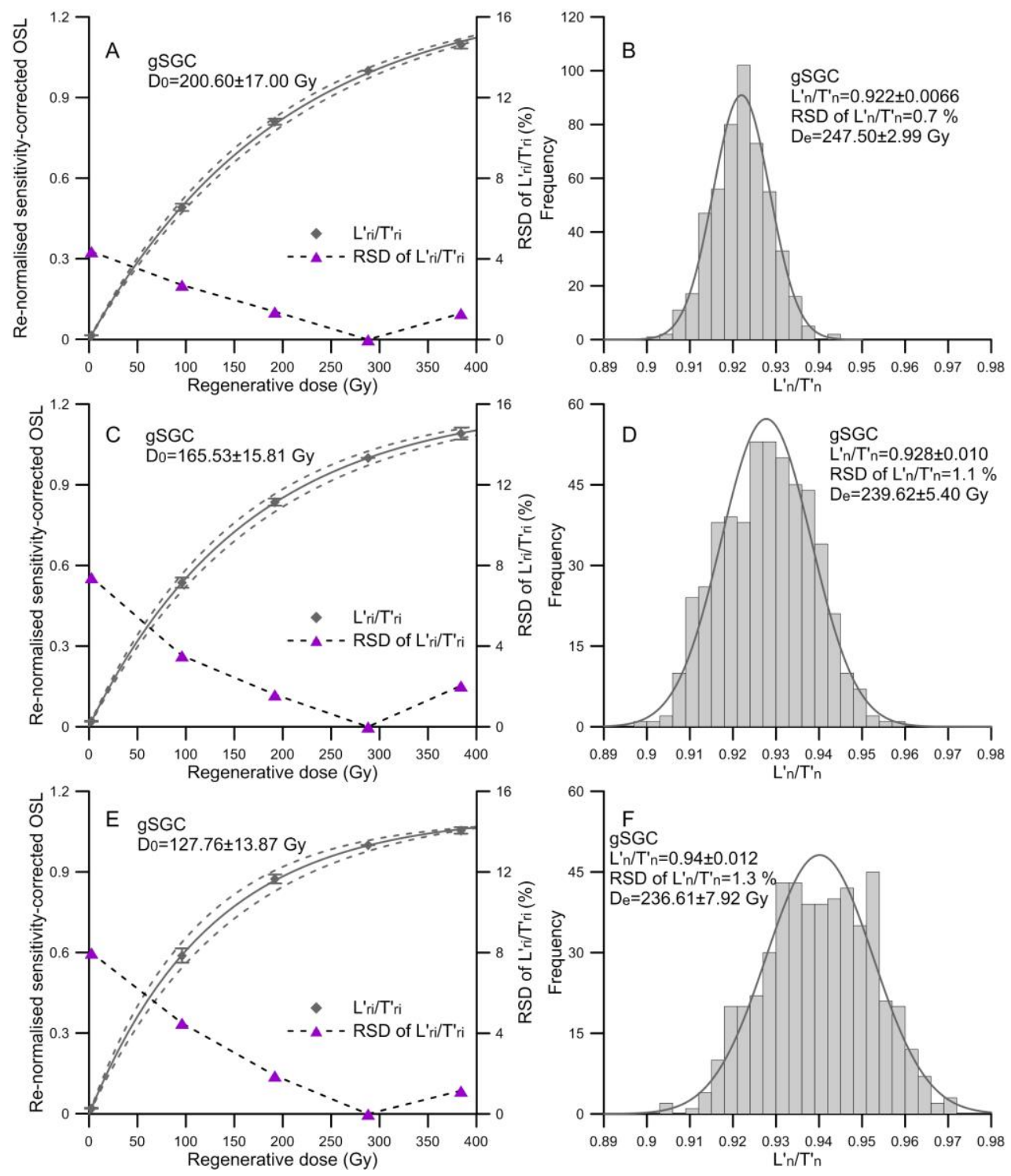

Fig. 5. The same data as in Fig. 4. (A), (C) and (E) were re-normalised using the fourth regenerative dose $\mathrm{D}_{\mathrm{r} 4}\left(\mathrm{~L}_{\mathrm{r}} / \mathrm{T}_{\mathrm{r} 4}\right)$ (i.e., $\left.\mathrm{L}_{\mathrm{r} /}^{\prime} / \mathrm{T}_{\mathrm{ri}}^{\prime}=\left[\mathrm{L}_{\mathrm{ri}} / \mathrm{T}_{\mathrm{ri}}\right] /\left[\mathrm{L}_{\mathrm{r}} / \mathrm{T}_{\mathrm{r} 4}\right]\right)$. (B), (D), and (F) show the distributions of re-normalised sensitivity-corrected given (natural) dose signal $\mathrm{L}_{\mathrm{n}} / \mathrm{T}_{\mathrm{n}}^{\prime}$. 

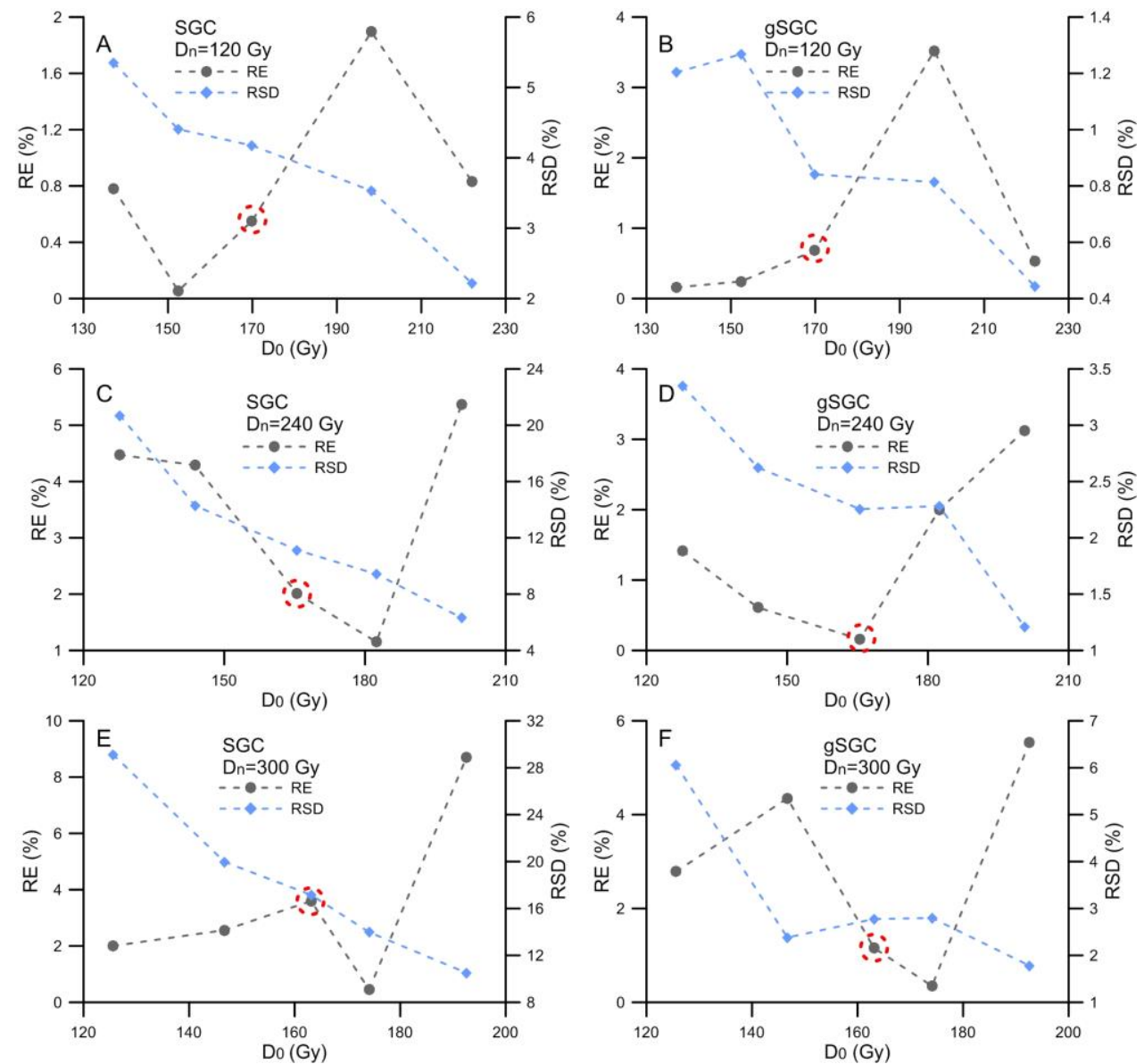

Fig. 6. Variation of RSD and RE of $S G C$ and gSGC $D_{e}$ estimates with $D_{0}\left(N_{8}\right)$ for various given doses $D_{n}$. Each data point was based on 500 versions of simulation. The data points encircled by dashed circles denote the RE of $D_{e}$ estimates simulated using the default $\mathrm{N}_{8}$ value of $1 \times 10^{11} \mathrm{~cm}^{-3}$. 

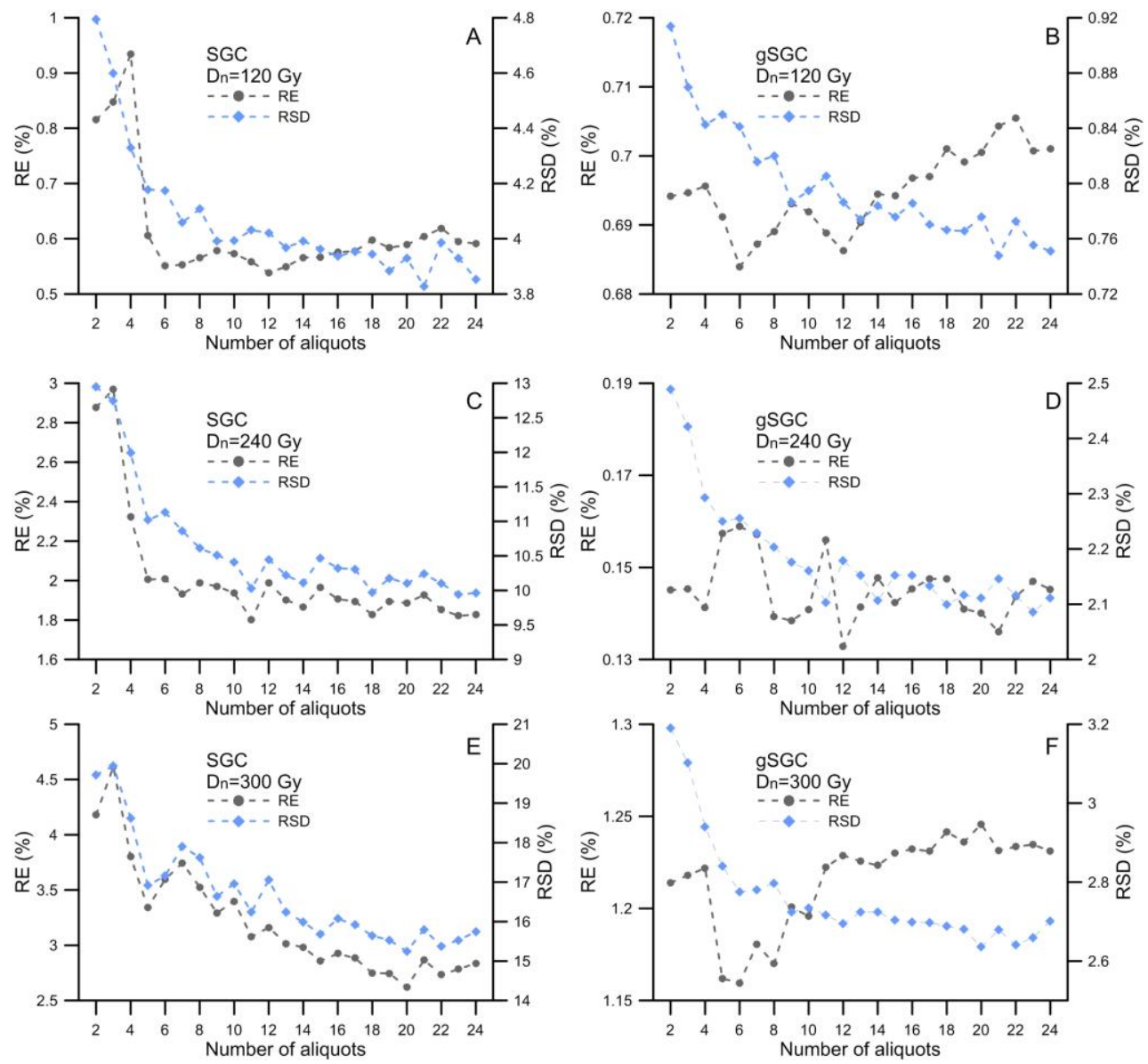

Fig. 7. Variation of RSD and RE of SGC and gSGC $D_{e}$ estimates with the number of aliquots used to establish the SGC and gSGC for various given doses $D_{n}$. The investigated number of aliquots ranges from 2 to 24 with an interval of 1 . Each data point was based on 500 model variants. 


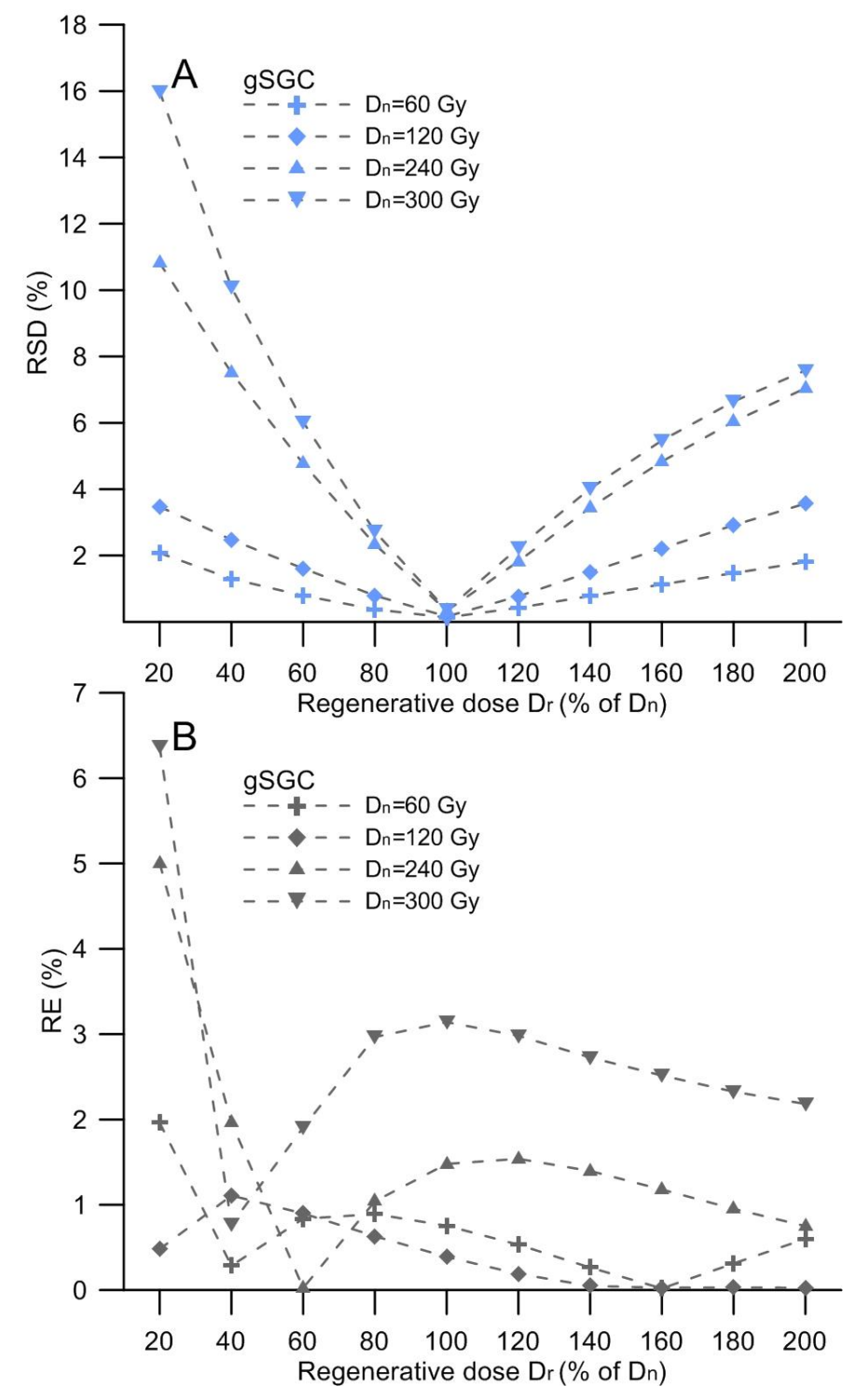

Fig. 8. Variation of RSD (A) and RE (B) of gSGC $D_{e}$ estimates with the size of the additional regenerative dose $D_{r}\left(L_{r} / T_{r}\right)$ used to re-normalise the sensitivity-corrected natural dose signal for various given doses $D_{n}$. $D_{r}$ ranges from $0.2 D_{n}$ to $2 D_{n}$ with a step of $0.2 D_{n}$. Each data point was based on 500 model variants. Note that the scales of $x$-axes are expressed as percent of the given dose $D_{n}$. 

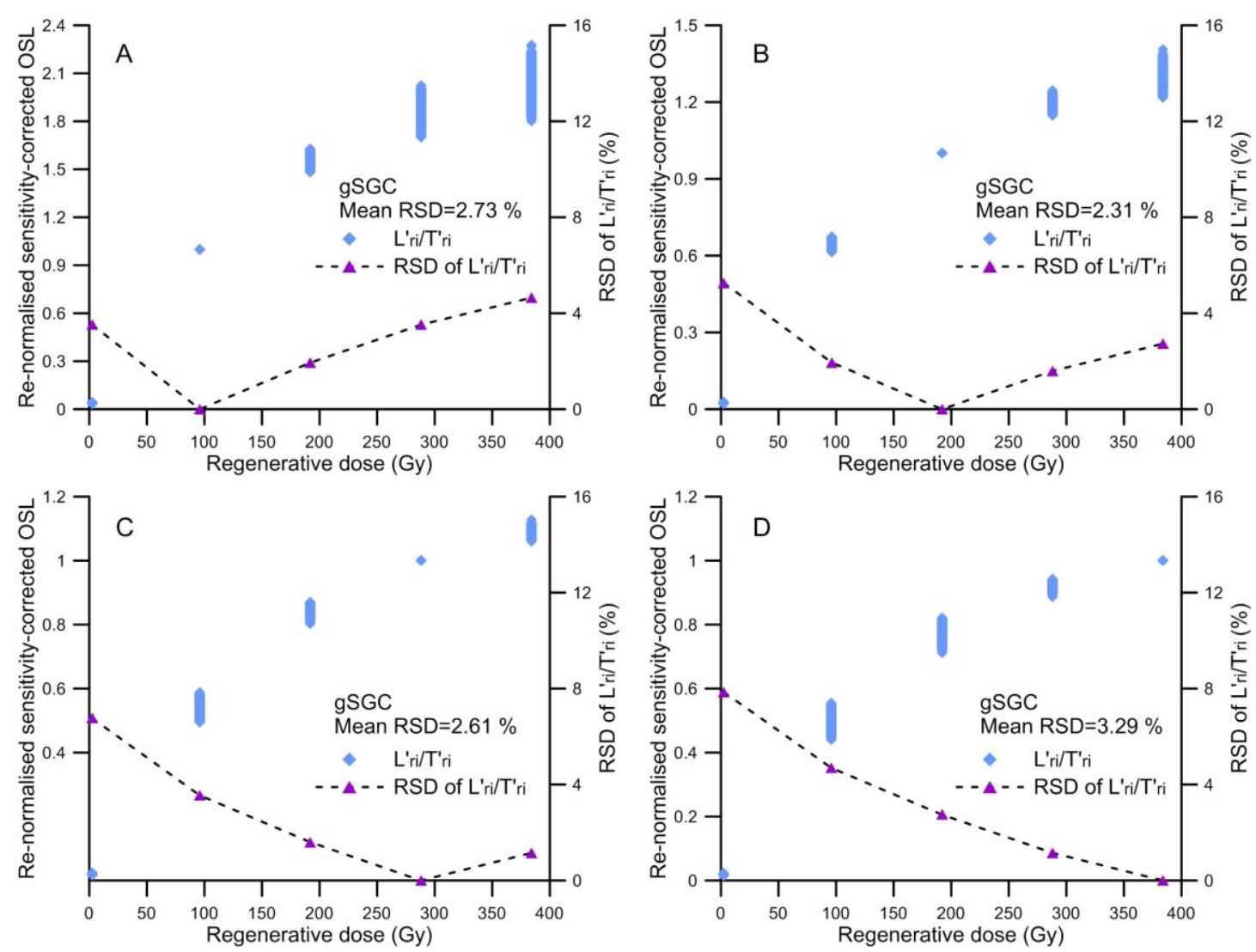

Fig. 9. Variation of re-normalised sensitivity-corrected regenerative dose signals $\mathrm{L}_{\mathrm{ri}}^{\prime} / \mathrm{T}_{\mathrm{ri}}^{\prime}$ with the size of regenerative dose $\mathrm{D}_{\mathrm{ri}}\left(\mathrm{L}_{\mathrm{r}} / \mathrm{T}_{\mathrm{ri}}\right)$ used for growth curve re-normalisation for a given dose of $240 \mathrm{~Gy}$. (A), (B), (C), and (D) were re-normalised using regenerative dose values of $0.4 \mathrm{D}_{\mathrm{n}}, 0.8 \mathrm{D}_{\mathrm{n}}$, $1.2 \mathrm{D}_{\mathrm{n}}$, and $1.6 \mathrm{D}_{\mathrm{n}} \mathrm{Gy}$ (Table 2), respectively. Each subplot was based on 3000 randomly simulated growth curves. 

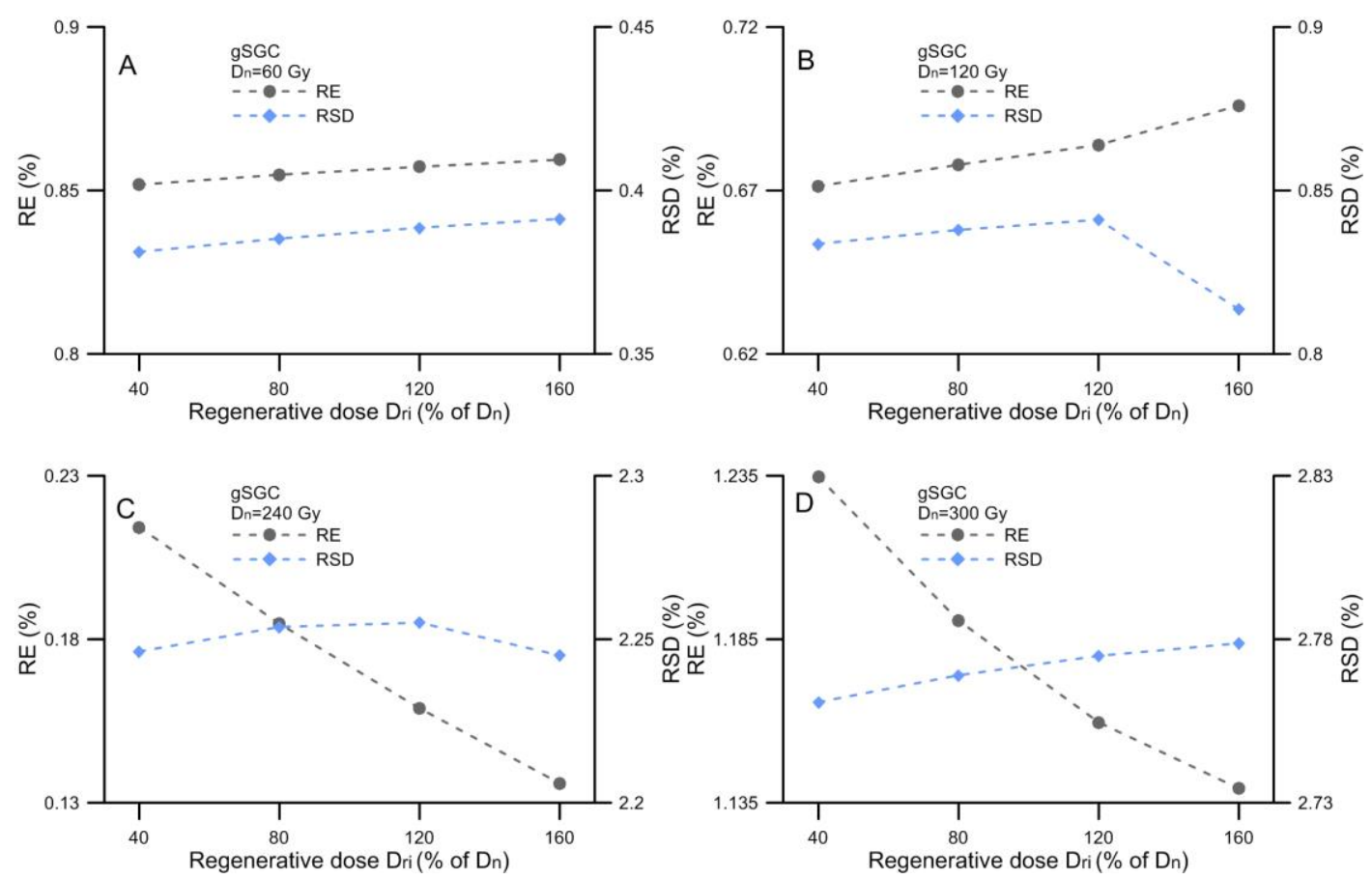

Fig. 10. Variation of RSD and RE of gSGC $D_{e}$ estimates with the size of the regenerative dose $D_{r i}$ $\left(\mathrm{L}_{\mathrm{r}} / T_{\mathrm{ri}}\right)$ used for growth curve re-normalisation for various given doses $\mathrm{D}_{\mathrm{n}}$. The four regenerative dose values used for re-normalisation are $0.4 \mathrm{D}_{\mathrm{n}}, 0.8 \mathrm{D}_{\mathrm{n}}, 1.2 \mathrm{D}_{\mathrm{n}}$, and $1.6 \mathrm{D}_{\mathrm{n}}$ Gy (Table 2). Each data point was based on 500 model variants. Note that the scales of $\mathrm{x}$-axes are expressed as percent of the given dose $D_{n}$. 